\title{
Functional Outcome and Quality of Life of Conservative Versus Surgical Management of Adult Potts Disease with Incomplete Spinal Cord Injury: A Prospective Cohort Study
}

\author{
Mark Maranon* and David Endriga \\ Philippine Orthopedic Center, Quezon City, Philippines \\ *Corresponding Author: Mark Maranon, Philippine Orthopedic Center, Quezon \\ City, Philippines.
}

Received: November 01, 2021

Published: November 10, 2021

(C) All rights are reserved by Mark Maranon and David Endriga .

\begin{abstract}
Objective: The aim of the study is to determine the differences in functional outcome and quality of life of adult patients with Potts disease with incomplete spinal cord injury who have undergone surgical versus non-surgical management.

Methods: In this prospective cohort study, 45 patients were followed up for 1 year after undergoing pharmacologic treatment alone versus a combination of anti-Kochs and surgery for Potts disease. Oswestry Disability Index (ODI) and Short Form-36 (SF-36) were obtained on initiation of treatment, after three months, six months and one year.

Results: ASIA scores from onset of treatment and after 1 year significantly improved $(\mathrm{p}<0.001)$ for both non-surgical and surgical patients. ODI scores showed significant improvement ( $p$ 0.004) after 6 months of treatment for both surgical (ODI 40.56 \pm 8.31 ) and non-surgical (ODI $50.81 \pm 12.43$ ) patients. At the end of one year for both groups, their disability classification improved from "crippled" to "moderate disability". For SF-36, patients who underwent surgery had significantly improved scores on the $3^{\text {rd }}$ month of treatment in the following domains: physical function ( $\mathrm{p}$ 0.002), physical role limitation $(\mathrm{p}<0.001)$, emotional role limitation ( $\mathrm{p}<$ 0.001 ), social functioning ( $p$ 0.003) and health change ( $p<0.001)$. After 1 year of treatment, patients in both groups ( $<<0.001)$ were noted to have significant improvement.

Conclusion: Significant improvement with regards to functional outcome and quality of life was noted from both surgical and nonsurgical patients after 1 year of treatment, with earlier improvements and better final scores in SF 36 and ODI in patients who underwent surgery.
\end{abstract}

Keywords: Tuberculosis; Spinal; Potts Disease; Functional Outcome

\section{Introduction}

The Philippines is currently ranked eighth in the top 20 countries with the highest number of tuberculosis cases. The country alone contributes to $3 \%$ of the global census having $1,379,390$ cases from 2003 to 2011 [1].

Of all the extra-pulmonary forms of the disease, spinal tuberculosis or Pott's disease is the most dangerous because it may lead to bone destruction of the vertebral body, spinal deformity, paraplegia and pulmonary insufficiency secondary to the deformity of thoracic cage. This ultimately leads to functional loss $[2,3]$.
Ideally, surgical management should be done in patients with neurological compromise, spinal deformity and signs of instability [4]. Debridement, bone grafting, and instrumented fixation are recommended in treating thoracic and lumbar tuberculosis complicated by kyphotic deformity and neurologic deficits $[5,6]$.

However, in developing countries like the Philippines, access to surgical management is difficult given that Potts disease more commonly affects those in the lower social classes. It is not uncommon, therefore, for patients who are surgical candidates end up being managed non-operatively with anti-Kochs medications

Citation: Mark Maranon and David Endriga . "Functional Outcome and Quality of Life of Conservative Versus Surgical Management of Adult Potts Disease with Incomplete Spinal Cord Injury: A Prospective Cohort Study". Acta Scientific Orthopaedics 4.12 (2021): 09-16. 
Functional Outcome and Quality of Life of Conservative Versus Surgical Management of Adult Potts Disease with Incomplete Spinal Cord Injury: A Prospective Cohort Study

alone. Although there have been improvements in symptoms [7,8] in patients treated with conservative management, there is still a paucity of literature [9] comparing the functional outcomes and quality of life of patients with Potts disease who have been treated with surgery and non-operatively.

In this study, the general objective was to compare the differences in outcome of adult patients with Potts disease with incomplete spinal cord injury who underwent surgical and conservative treatment. Specifically, we used the Oswestry Disability Index and Short Form 36 for functional outcome and quality of life.

\section{Materials and Methods}

This is a prospective, observational cohort study performed at a single institution. Approval from the hospital's ethics committee was obtained. A minimum of 32 patients was required for this study based on a $5 \%$ level of significance and $80 \%$ power with an assumed desired large effect size between surgical and conservative group in terms of functional outcome and quality of life. The computed sample size assumes that the proportion of patients to be assigned to the two groups is equal based on previous local hospital data.

Only patients with incomplete spinal cord injury (with preservation of sensory or motor function below the level of injury, including the lowest sacral segments) were included in the study. Patients with multi-drug resistant TB (MDR TB) would be excluded from the study. Patients with cervical involvement, quadriplegia, manual muscle test of $0 / 5$ on admission and residing outside Metropolitan Manila were excluded from the study. Convenience Sampling was done and included 45 adult patients (20-65 years old) admitted in Philippine Orthopedic Center from 2018 to 2021 confirmed by histology through CT-guided biopsy with Potts disease undergoing anti Koch's therapy. Of the 45 patients, 18 patients underwent surgery and 27 patients underwent conservative management.

Conservative management consists of 12 months of antituberculous medications along with supportive measures like standardized physical therapy and application of spinal orthoses, as provided by the Rehabilitation Department of the institution. The 12-month regimen includes two months of intensive phase of firstline drugs: isoniazid, rifampicin, pyrazinamide and ethambutol and 10 months of continuation phase using isoniazid and rifampicin under the direct supervision of the TB DOTS (Tuberculosis Directly Observed Treatment, Short-course) [10,11].
On admission, informed consent and baseline clinical information and demographics were obtained. Oswestry Disability Index [12-15] and SF-36 [16-18] were recorded at the time of initiation of treatment, 3 months, 6 months and 1 year after intervention (surgical vs non-surgical management).

Functional outcome was measured using the Oswestry Disability Index (ODI), a valid, reliable and condition-specific tool $[18,19]$ to measure disability in patients with back pain with a wide range of severity and causes. A final ODI score ranges from 0-100 with a higher score indicating a more severe disability (0-20: minimal disability; 20-40: moderate disability; 41-60: severe disability; 61-80: crippled; 81-100: bed bound).

Quality of life was measured using the 36-Item Short Form (SF36), which is one of the instruments that has been widely used to measure health related quality of life (HRQoL) in patients with chronic conditions [16-18]. SF-36 has eight domains - Physical functioning, Role limitations due to physical health, Role limitations due to emotional problems, Energy, Emotional well-being, Social functioning, Pain, General health and Perceived health change. Each domain has a perfect score of 100 .

\section{Statistical analysis}

Descriptive statistics was used to summarize the demographic and clinical characteristics of the patients. Frequency and proportion was used for categorical variables, median and inter quartile range for non-normally distributed continuous variables, and mean and SD for normally distributed continuous variables. Independent Sample T-test, Mann-Whitney U test and Fisher's Exact/ Chi-square test was used to determine the difference of mean, rank and frequency, respectively, between surgical and non-surgical patients. McNemar test was used to determine the difference from prior to treatment to after 1 year in terms of ASIA Score. Repeated measures analysis of variance was used to determine the difference of Oswestry Disability Index from prior to treatment to after 1 year. Friedman test was used to determine the difference among different Short Form 36 domain responses of the patients from the time of treatment to 1 year after follow-up. All statistical tests were two tailed test. Shapiro-Wilk was used to test the normality of the continuous variables. Missing values were neither replaced nor estimated. Null hypotheses were rejected at $0.05 \alpha$-level of significance. STATA 13.1 was used for data analysis. 
Functional Outcome and Quality of Life of Conservative Versus Surgical Management of Adult Potts Disease with Incomplete Spinal Cord Injury: A Prospective Cohort Study

\section{Results}

Table 1 shows that the characteristics - age, sex, level of vertebra affected and duration of symptoms prior to seeking treatment - of patients included in the study are comparable. The subjects had a mean age $42.09 \pm 9.57$ years and majority (55\%) were males. In most of the patients, the thoracic vertebra was affected, accounting for $66.67 \%$ of patients. Duration of symptoms prior to seeking treatment was $2.96 \pm 1.81$ months.

\begin{tabular}{|l|c|c|c|c|}
\hline \multirow{2}{*}{ Age } & $\begin{array}{c}\text { Total } \\
\text { (n= 45) }\end{array}$ & $\begin{array}{c}\text { Surgical } \\
\text { (n= 18) }\end{array}$ & $\begin{array}{c}\text { Non-Surgical } \\
\text { (n = 27) }\end{array}$ & $\begin{array}{c}\text { P } \\
\text { value }\end{array}$ \\
\cline { 2 - 4 } Sex & \multicolumn{2}{|c|}{ Frequency (\%); Mean \pm SD } & \\
\hline Male & $42.09 \pm 9.57$ & $41.17 \pm 8.64$ & $42.70 \pm 10.27$ & 0.604 \\
\hline Female & $25(55.56)$ & $9(50)$ & $16(59.26)$ & 0.559 \\
\hline Level affected & $20(44.44)$ & $9(50)$ & $11(40.74)$ & \\
Thoracic & $30(66.67)$ & $9(50)$ & $21(77.78)$ & \\
Lumbar & $7(15.56)$ & $4(22.22)$ & $3(11.11)$ & \\
\hline $\begin{array}{l}\text { Thoracolumbar } \\
\text { Lumbosacral }\end{array}$ & $6(13.33)$ & $4(22.22)$ & $2(7.41)$ & \\
\hline $\begin{array}{l}\text { Duration of } \\
\text { symptoms } \\
\text { (months) prior } \\
\text { to treatment }\end{array}$ & $2.96 \pm 1.81$ & $2.72 \pm 1.53$ & $3.11 \pm 1.99$ & \\
\hline
\end{tabular}

Table 1: Patient characteristics.

ASIA scores from onset of treatment and after 1 year significantly improved for both non-surgical ( $p$ value 0.003 ) and surgical patients ( $\mathrm{p}$ value $<0.001$ ) (Table 2 ).

For ODI, mean score for all patients at the start of treatment was $77.33 \pm 10.92$ corresponding to "crippled". Results also showed that on the $6^{\text {th }}$ month of treatment, ODI scores significantly improved for both surgical and non-surgical patients ( $p$ value 0.004 ) but scores were significantly better in the group of patients who underwent surgery (ODI $40.56 \pm 8.31$ ) compared to those who did not (ODI $50.81 \pm 12.43$ ). After one year, there was marked improvement of mean ODI score $(31.82 \pm 11.22 \mathrm{p}$ value 0.036$)$ for both groups, improving their disability classification from "crippled" to

\begin{tabular}{|c|c|c|c|c|}
\hline & $\begin{array}{c}\text { Total } \\
(n=45)\end{array}$ & $\begin{array}{l}\text { Surgical } \\
(n=18)\end{array}$ & $\begin{array}{c}\text { Non-Surgical } \\
(n=27)\end{array}$ & \multirow[t]{2}{*}{$\begin{array}{c}\text { P- } \\
\text { value }\end{array}$} \\
\hline & \multicolumn{3}{|c|}{ Frequency (\%) } & \\
\hline Prior to treatment & & & & 0.293 \\
\hline A & 0 & 0 & 0 & \\
\hline B & $4(8.89)$ & $3(16.67)$ & $1(3.70)$ & \\
\hline $\mathrm{C}$ & $24(53.33)$ & $10(55.56)$ & $14(51.85)$ & \\
\hline $\mathrm{D}$ & $17(37.78)$ & $5(27.78)$ & $12(44.44)$ & \\
\hline $\mathrm{E}$ & 0 & 0 & 0 & \\
\hline After 1 year & & & & 0.302 \\
\hline A & 0 & 0 & 0 & \\
\hline B & 0 & 0 & 0 & \\
\hline $\mathrm{C}$ & $4(8.89)$ & 0 & $4(14.81)$ & \\
\hline D & $28(62.22)$ & 12 (66.67) & $16(59.26)$ & \\
\hline E & $13(28.89)$ & $6(33.33)$ & 7 (25.93) & \\
\hline $\begin{array}{l}\text { P-value for ASIA } \\
\text { Score from prior } \\
\text { to treatment to } \\
\text { after } 1 \text { year }\end{array}$ & $<0.001$ & $<0.001$ & 0.003 & \\
\hline
\end{tabular}

Table 2: ASIA Score from start of treatment and after 1 year.

"moderate disability" with significantly higher mean ODI score for patients who underwent surgery $(27.56 \pm 6.95)$ compared to nonsurgical patients $(34.67 \pm 12.67)$ (Table 3$)$.

For SF-36, patients who underwent surgery had significantly improved scores on the $3^{\text {rd }}$ month of treatment in the following domains: physical function ( $\mathrm{p}$ 0.002), physical role limitation ( $\mathrm{p}$ $<0.001)$, emotional role limitation $(<0.001)$, social functioning ( $p$ $0.003)$ and health change $(p<0.001)$. After 1 year of treatment, patients in both groups $(\mathrm{p}<0.001)$ were noted to have significant improvement compared to their scores at the start of treatment. Although both surgical and non-surgical patients were able to achieve higher scores after 1 year, scores were significantly higher in patients who underwent surgical management (Table 4).

No surgical complications and deaths were noted after 1 year in all patients. 
Functional Outcome and Quality of Life of Conservative Versus Surgical Management of Adult Potts Disease with Incomplete Spinal Cord Injury: A Prospective Cohort Study

\begin{tabular}{|c|c|c|c|c|}
\hline & $\begin{array}{c}\text { Total } \\
(n=45)\end{array}$ & $\begin{array}{l}\text { Surgical } \\
(n=18)\end{array}$ & $\begin{array}{c}\text { Non-Surgical } \\
(n=27)\end{array}$ & D.uolu \\
\hline & & uency (\%); M & SD & P-value \\
\hline At start of treatment & $77.33 \pm 10.92$ & $80.56 \pm 6.71$ & $75.19 \pm 12.66$ & 0.107 \\
\hline Minimal disability & 0 & 0 & 0 & 0.120 \\
\hline Moderate & 0 & 0 & 0 & \\
\hline Severe & $6(13.33)$ & 0 & $6(22.22)$ & \\
\hline Crippled & 13 (28.89) & $6(33.33)$ & $7(25.93)$ & \\
\hline Bed bound & $26(57.78)$ & $12(66.67)$ & $14(51.85)$ & \\
\hline At $3^{\text {rd }}$ month & $62.4 \pm 10.59$ & $60 \pm 8.15$ & $64 \pm 11.82$ & 0.218 \\
\hline Minimal disability & 0 & 0 & 0 & 0.768 \\
\hline Moderate & $2(4.44)$ & $1(5.56)$ & $1(3.70)$ & \\
\hline Severe & $17(37.78)$ & $8(44.44)$ & $9(33.33)$ & \\
\hline Crippled & $26(57.78)$ & $9(50)$ & $17(62.96)$ & \\
\hline Bed bound & 0 & 0 & 0 & \\
\hline At $6^{\text {th }}$ month & $46.71 \pm 11.99$ & $40.56 \pm 8.31$ & $50.81 \pm 12.43$ & 0.004 \\
\hline Minimal disability & 0 & 0 & 0 & 0.120 \\
\hline Moderate & 13 (28.89) & $6(33.33)$ & $7(25.93)$ & \\
\hline Severe & $26(57.78)$ & $12(66.67)$ & $14(51.85)$ & \\
\hline Crippled & $6(13.33)$ & 0 & $6(22.22)$ & \\
\hline Bed bound & 0 & 0 & 0 & \\
\hline At $1^{\text {st }}$ year & $31.82 \pm 11.22$ & $27.56 \pm 6.95$ & $34.67 \pm 12.67$ & 0.036 \\
\hline Minimal disability & $9(20)$ & $5(27.78)$ & $4(14.81)$ & 0.095 \\
\hline Moderate & $29(64.44)$ & $13(72.22)$ & $16(59.26)$ & \\
\hline Severe & $6(13.33)$ & 0 & $6(22.22)$ & \\
\hline Crippled & $1(2.22)$ & 0 & $1(3.70)$ & \\
\hline Bed bound & 0 & 0 & 0 & \\
\hline $\begin{array}{l}\text { P-value for Oswestry } \\
\text { Disability Index from } \\
\text { prior to treatment to } \\
\text { after } 1 \text { year }\end{array}$ & $<0.001$ & $<0.001$ & $<0.001$ & \\
\hline
\end{tabular}

Table 3: Oswestry Disability Index from start of treatment to 1 year. 
Functional Outcome and Quality of Life of Conservative Versus Surgical Management of Adult Potts Disease with Incomplete Spinal Cord Injury: A Prospective Cohort Study

\begin{tabular}{|c|c|c|c|c|}
\hline & $\begin{array}{c}\text { Total } \\
(n=45)\end{array}$ & $\begin{array}{l}\text { Surgical } \\
(n=18)\end{array}$ & $\begin{array}{c}\text { Non-Surgical } \\
\quad(n=27)\end{array}$ & \multirow[t]{2}{*}{ P-value } \\
\hline & \multicolumn{3}{|c|}{ Median (IQR) } & \\
\hline \multicolumn{5}{|c|}{ Physical function } \\
\hline At treatment & $0(0$ to 25$)$ & 0 & 0 (0 to 25$)$ & 0.056 \\
\hline At $3^{\text {rd }}$ month & $10(0$ to 15$)$ & $10(10$ to 15$)$ & 5 (0 to 10$)$ & 0.002 \\
\hline At $6^{\text {th }}$ month & 25 (15 to 30$)$ & 30 (25 to 35$)$ & 15 (10 to 25$)$ & $<0.001$ \\
\hline At $1^{\text {st }}$ year & $30(20$ to 40$)$ & $40(35$ to 40$)$ & 25 (20 to 35$)$ & 0.001 \\
\hline P-value & $<0.001$ & $<0.001$ & $<0.001$ & \\
\hline \multicolumn{5}{|c|}{ Role limitation-physical } \\
\hline At treatment & 0 & 0 & 0 & - \\
\hline At $3^{\text {rd }}$ month & 25 (0 to 25$)$ & 25 (25 to 50 ) & 0 (0 to 25$)$ & $<0.001$ \\
\hline At $6^{\text {th }}$ month & 25 (25 to 50$)$ & 50 (25 to 50$)$ & $25(0$ to 25$)$ & $<0.001$ \\
\hline At $1^{\text {st }}$ year & $50(50$ to 75$)$ & 75 (50 to 75$)$ & $50(25$ to 50$)$ & $<0.001$ \\
\hline P-value & $<0.001$ & $<0.001$ & $<0.001$ & \\
\hline \multicolumn{5}{|c|}{ Role limitation-emotional } \\
\hline At treatment & $0(0$ to 33.3$)$ & 0 & $0(0$ to 33.3$)$ & 0.148 \\
\hline At $3^{\text {rd }}$ month & $0(0$ to 33.3$)$ & 33.3 (0 to 66.7$)$ & $0(0$ to 33.3$)$ & $<0.001$ \\
\hline At $6^{\text {th }}$ month & 33.3 (33.3 to 66.7 ) & 66.7 (33.3 to 66.7 ) & $33.3(0$ to 33.3$)$ & $<0.001$ \\
\hline At $1^{\text {st }}$ year & 66.7 (33.3 to 66.7) & 66.7 (33.3 to 100$)$ & $66.7(33.3$ to 66.7$)$ & 0.003 \\
\hline P-value & $<0.001$ & $<0.001$ & $<0.001$ & \\
\hline \multicolumn{5}{|l|}{ Energy } \\
\hline At treatment & $40(35$ to 45$)$ & 25 (25 to 35$)$ & $40(40$ to 45$)$ & $<0.001$ \\
\hline At $3^{\text {rd }}$ month & $40(40$ to 50$)$ & 47.5 (40 to 50$)$ & $50(40$ to 45$)$ & 0.223 \\
\hline At $6^{\text {th }}$ month & 45 (40 to 50$)$ & $50(45$ to 55$)$ & 45 (50 to 50$)$ & 0.052 \\
\hline At $1^{\text {st }}$ year & $50(40$ to 50$)$ & $50(45$ to 55$)$ & $45(40$ to 50$)$ & 0.285 \\
\hline P-value & $<0.001$ & $<0.001$ & $<0.001$ & \\
\hline
\end{tabular}

Citation: Mark Maranon and David Endriga . "Functional Outcome and Quality of Life of Conservative Versus Surgical Management of Adult Potts Disease with Incomplete Spinal Cord Injury: A Prospective Cohort Study". Acta Scientific Orthopaedics 4.12 (2021): 09-16. 
Functional Outcome and Quality of Life of Conservative Versus Surgical Management of Adult Potts Disease with Incomplete Spinal Cord Injury: A Prospective Cohort Study

\begin{tabular}{|c|c|c|c|c|}
\hline \multicolumn{5}{|c|}{ Emotional well-being } \\
\hline At treatment & $52(48$ to 56$)$ & $46(40$ to 48$)$ & $56(48$ to 60$)$ & $<0.001$ \\
\hline At $3^{\text {rd }}$ month & $56(48$ to 60$)$ & $52(48$ to 60$)$ & $56(48$ to 60$)$ & 0.366 \\
\hline At $6^{\text {th }}$ month & $56(52$ to 60$)$ & $56(52$ to 60$)$ & $56(52$ to 60$)$ & 0.437 \\
\hline At $1^{\text {st }}$ year & $56(52$ to 60$)$ & $56(52$ to 60$)$ & $60(56$ to 60$)$ & 0.237 \\
\hline P-value & 0.039 & $<0.001$ & 0.260 & \\
\hline \multicolumn{5}{|c|}{ Social functioning } \\
\hline At treatment & 37.5 (25 to 50$)$ & 31.25 (25 to 50$)$ & 37.5 (25 to 50$)$ & 0.304 \\
\hline At $3^{\text {rd }}$ month & $50(37.5$ to 50$)$ & 50 (50 to 62.5$)$ & 37.5 (25 to 50$)$ & 0.003 \\
\hline At $6^{\text {th }}$ month & $50(37.5$ to 62.5$)$ & 62.5 (50 to 75$)$ & 37.5 (37.5 to 50$)$ & $<0.001$ \\
\hline At $1^{\text {st }}$ year & $50(37.5$ to 62.5$)$ & 75 (62.5 to 75$)$ & 37.5 (37.5 to 62.5$)$ & $<0.001$ \\
\hline P-value & $<0.001$ & $<0.001$ & 0.251 & \\
\hline \multicolumn{5}{|l|}{ Pain } \\
\hline At treatment & 22.5 (12.5 to 45$)$ & 10 (10 to 22.5$)$ & 32.5 (22.5 to 45$)$ & $<0.001$ \\
\hline At $3^{\text {rd }}$ month & 45 (32.5 to 55$)$ & 55 (45 to 67.5 ) & 45 (22.5 to 45$)$ & $<0.001$ \\
\hline At $6^{\text {th }}$ month & 67.5 (45 to 77.5 ) & 77.5 (67.5 to 77.5$)$ & 45 (45 to 67.5$)$ & $<0.001$ \\
\hline At $1^{\text {st }}$ year & 77.5 (67.5 to 77.5$)$ & 77.5 (77.5 to $87.5_{-}$ & 67.5 (32.5 to 67.5$)$ & $<0.001$ \\
\hline P-value & $<0.001$ & & & \\
\hline \multicolumn{5}{|l|}{ General health } \\
\hline At treatment & 20 (15 to 25$)$ & 15 (15 to 20$)$ & 25 (20 to 30$)$ & 0.004 \\
\hline At $3^{\text {rd }}$ month & 35 (25 to 45$)$ & 50 (45 to 50$)$ & 25 (20 to 35$)$ & $<0.001$ \\
\hline At $6^{\text {th }}$ month & 45 (35 to 55$)$ & 55 (50 to 65$)$ & $35(30$ to 40$)$ & $<0.001$ \\
\hline At $1^{\text {st }}$ year & $60(50$ to 65$)$ & 65 (65 to 70$)$ & 55 (45 to 60$)$ & $<0.001$ \\
\hline P-value & $<0.001$ & $<0.001$ & $<0.001$ & \\
\hline \multicolumn{5}{|l|}{ Health change } \\
\hline At treatment & $0(0$ to 25$)$ & 0 & $0(0$ to 25$)$ & 0.215 \\
\hline At $3^{\text {rd }}$ month & $25(0$ to 25$)$ & $25(0$ to 25$)$ & $0(0$ to 25$)$ & $<0.001$ \\
\hline At $6^{\text {th }}$ month & $25(25$ to 50$)$ & $50(25$ to 50$)$ & 25 (25 to 75$)$ & $<0.001$ \\
\hline At $1^{\text {st }}$ year & 75 (75 to 100$)$ & 87.5 (75 to100) & 75 (75 to 100$)$ & 0.155 \\
\hline P-value & $<0.001$ & $<0.001$ & $<0.001$ & \\
\hline
\end{tabular}

Table 4: Short Form 36 from start of treatment to 1 year. 


\section{Discussion}

In this study, we documented a total of 45 spinal tuberculosis patients with incomplete spinal cord injury who are all candidates for surgery. 18 of them underwent surgery and 27 underwent conservative management. Our results revealed that both ODI and SF36 scores significantly improved after one year in both groups of patients. However, final functional outcome scores and quality of life scores were significantly better in the group that underwent surgery. The improvement in the scores were also reflected earlier in patients treated with surgical management.

In our institution, from 2014-2017, an average of 60.2 Filipino adult patients were admitted every year for spinal tuberculosis. $76.5 \%$ presented with incomplete spinal cord injury and radiographic evidences of instability. Despite being candidates for surgery, not all patients undergo surgery mostly because of financial difficulties. $92 \%$ of patients admitted were classified as low-income or indigent. These patients undergo anti-Kochs regimen supervised by the hospital's Tuberculosis Directly Observed Treatment Short course (TB DOTS) department. Despite not undergoing surgery, improvement of symptoms is still reported by patients after completion of treatment. No known studies have documented and compared the differences in functional outcome and quality of life of spinal tuberculosis patients who underwent surgery versus nonsurgical management.

To date, controversy remains regarding what constitutes the optimal treatment for patients with spinal tuberculosis [17] but surgery remains the preferred mode of treatment for patients with spinal instability, neurologic deficit and significant kyphosis [18]. The advantages of surgery include thoroughness of debridement, decompression of the spinal cord and adequate spinal stabilization [19]. This explains why patients that underwent surgery in this study showed earlier improvement in functional outcome, quality of life scores and neurologic status compared to patients that were managed conservatively.

There are only two available studies - by Shetty., et al. in 2019 and by Jiang., et al. in 2015 - that showed significant improvement in functional outcome using ODI scores and neurologic status using ASIA scores in patients treated conservatively and surgically $[19,20]$. However, patients that showed significant improvement in these studies have mild presenting symptoms of low back pain and no signs of instability.
Numerous studies have been published that showed better ODI [21-24] and SF-36 [25] scores in patients undergoing surgery regardless of the surgical approach but none has been published yet that compared functional outcomes and quality of life in patients presenting with neurologic deficits and spinal instability.

A limitation of this study is the sample size given that the study participants were recruited in a single institution. We recommend a multi-center study to increase the number of sample size and also take into account the different surgical techniques of different institutions and compare outcomes. This study also focused only on the functional outcome and quality of life after 1 year of intervention. Succeeding studies could also include the comparison of progression of vertebral kyphosis from initiation of treatment until 1 year [26-28].

\section{Conclusion}

After one year of treatment, significant improvement in functional outcome and quality of life was noted in both surgical and non-surgical patients. Improvements were noted earlier and scores were higher in both SF 36 and ODI in surgical patients. For non-surgical patients, significant improvement in ODI and SF-36 were noted later in the treatment but was comparable to surgically treated patients after one year.

\section{Bibliography}

1. Vianzon R., et al. "The tuberculosis profile of the Philippines, 2003-2011: advancing DOTS and beyond". Western Pacific Surveillance and Response Journal 4.2 (2013).

2. Moon M-S. “Tuberculosis of Spine: Current Views in Diagnosis and Management". Asian Spine Journal 8.1 (2014): 97-111.

3. Zhang X., et al. "Management of spinal tuberculosis: a systematic review and meta-analysis". Journal of International Medical Research 41.5 (2013): 1395-1407.

4. Mak KC and Cheung KM. "Surgical treatment of acute TB spondylitis: indications and outcomes". European Spine Journal 22 (2013): 603-611.

5. Hu Jiang., et al. "Surgical treatment of thoracic and lumbar tuberculosis complicated with severe kyphotic deformity and paraplegia". Zhongguo xiu fu chong jian wai ke za zhi = Zhongguo xiufu chongjian waike zazhi = Chinese Journal of Reparative and Reconstructive Surgery 28 (2014): 1110-1114. 
6. Jutte PC and Van Loenhout-Rooyackers JH. "Routine surgery in addition to chemotherapy for treating spinal tuberculosis". Cochrane Database System Review (2006): CD004532.

7. Medeiros RS., et al. "Treatment of spinal tuberculosis: conservative or surgical?" Acta Ortopedica Brasileira 15.3 (2007): 128-131.

8. Zhang Z., et al. "The outcomes of chemotherapy only treatment on mild spinal tuberculosis". Journal of Orthopaedic Surgery and Research 11 (2016): 49.

9. Fisahn C., et al. "Trends in Spinal Surgery for Pott's Disease (2000-2016): An Overview and Bibliometric Study". Global Spine Journal 7.8 (2017): 821-828.

10. Task Force. Clinical Practice Guidelines for the Diagnosis, Treatment, Prevention and Control of Tuberculosis in Adult Filipinos: 2016 Update (CPGTB2016). Philippine Coalition Against Tuberculosis (PhilCAT), Philippine Society for Microbiology and Infectious Diseases (PSMID), Philippine College of Chest Physicians (PCCP).

11. Garg R K and Somvanshi D S. "Spinal tuberculosis: a review". The Journal of Spinal Cord Medicine 34.5 (2011): 440-454.

12. Bombardier C. "Spine focus issue introduction. Outcome assessments in the evaluation of treatment of spinal disorders". Spine 25 (2000): 3097-3099.

13. Deyo RA., et al. "Outcome measures for low back pain research. A proposal for standardized use”. Spine 23 (1998): 2003-2013.

14. Roland M and Fairbank J. "The Roland-Morris disability questionnaire and the Oswestry disability questionnaire". Spine 25 (2000): 3115-3124.

15. Vianin M. "Psychometric properties and clinical usefulness of the Oswestry Disability Index". Journal of Chiropractic Medicine 7.4 (2008): 161-163.

16. Hayes CJ., et al. "Reliability and Validity of the Medical Outcomes Study Short Form-12 Version 2 (SF-12v2) in Adults with Non-Cancer Pain". Svenson L, ed. Healthcare 5.2 (2017): 22.

17. Bunevicius A. "Reliability and validity of the SF-36 Health Survey Questionnaire in patients with brain tumors: a cross-sectional study". Health and Quality of Life Outcomes 15 (2017): 92.

18. Megan Davidson., et al. "A Comparison of Five Low Back Disability Questionnaires: Reliability and Responsiveness". Physical Therapy 82.1 (2002): 8-24.
19. Davidson M and Keating J L. "A comparison of five low back disability questionnaires: reliability and responsiveness". Physical Therapy 82.1 (2002): 8-24.

20. Pandita A., et al. "Challenges and controversies in the treatment of spinal tuberculosis". Journal of Clinical Tuberculosis and Other Mycobacterial Diseases 19 (2020): 100151.

21. Jain AK and Kumar J. "Tuberculosis of spine: neurological deficit”. European Spine Journal 22 (2013): 624-633.

22. Yong LN., et al. "Functional Outcomes in Spinal Tuberculosis: A Review of Literature”. Asian Spine Journal 15.3 (2021): 381391.

23. Jiang T., et al. "Outcomes and Treatment of Lumbosacral Spinal Tuberculosis: A Retrospective Study of 53 Patients". PLOS ONE 10.6 (2015): e0130185.

24. Singh S., et al. "Functional and radiological outcomes of anterior decompression and posterior stabilization via posterior transpedicular approach in thoracic and thoracolumbar Pott's disease: a retrospective study". Asian Spine Journal 11 (2017): 618-626.

25. Ran B., et al. "One-stage surgical treatment for thoracic and lumbar Spinal tuberculosis by transpedicular fixation, debridement, and combined interbody and posterior fusion via a posterior-only approach". Journal of Huazhong University of Science and Technology 36 (2016): 541-547.

26. Wu W., et al. "Surgical treatment of thoracic spinal tuberculosis: a multicenter retrospective study". World Neurosurgery 110 (2018): e842-850.

27. Shetty AP., et al. "Does preserving or restoring lumbar lordosis have an impact on functional outcomes in tuberculosis of the lumbosacral region?" Spine Deform 7 (2019): 356-363.

28. Li W., et al. "Posterior intervertebral space debridement, annular bone grafting and instrumentation for treatment of lumbosacral tuberculosis". BMC Surgery 17 (2017): 124.

\section{Volume 4 Issue 12 December 2021 (c) All rights are reserved by Mark Maranon and David Endriga .}

